\title{
The Development and Delivery of a Multidisciplinary Research Course for First-Year International Science Students
}

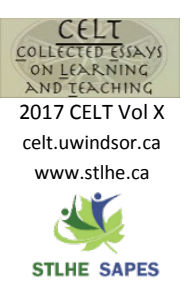

\author{
Priyanka Lekhi, Meghan Allen, Fok-Shuen Leung, Brett Gilley, Georg Rieger, \\ and Joanne A. Fox \\ University of British Columbia \\ DOI: $10.22329 /$ celt.v10i0.4734
}

Students who engage in undergraduate research experiences acquire many benefits, including an understanding of how scientific knowledge is constructed, recognition that knowledge can be complex and uncertain, and the habit of viewing knowledge critically. This paper describes a first-year twocourse sequence that provides multidisciplinary opportunities for international science students to engage in the research process and present at a student-led research conference. We describe course goals and structure, and discuss whether the goals were attained using instructor reflections, student performance, and student survey data. We also evaluate the impact of changes to the curriculum between Year 1 and Year 2. In both years, we found that students engaged meaningfully with the research process and began to understand how scientific knowledge is created. We also found that a modular model with front-end support worked better for instructors as compared to a continuous individualized project mentorship model. This modular approach involved structured pre-and postclass assignments within discipline-specific themes containing examples of the research process embedded into the discipline. These discipline-specific modules were followed by modules covering broader research process themes. We encourage instructors who are thinking of delivering a similar research-based course for first-year students to provide support via example research questions and other example templates for student submissions.

$\mathbf{T}^{\mathrm{t}}$ is important for undergraduate science students to 1 develop an understanding of how scientific knowledge is constructed, to begin viewing science as complex and vulnerable to criticism, and to start seeing themselves as potential contributors (Fox et al., 2014; Magolda, 2006; Wieman, 2012). This set of goals is epistemic in nature (i.e. related to views of knowledge) (Hofer \& Pintrich, 1997). On a course level, active learning techniques and undergraduate research opportunities are effective ways to achieve these goals (Healey \& Jenkins, 2009; Schalk, McGinnis, Harring, Hendrickson, \& Smith, 2009;
Thiry, Laursen, \& Hunter, 2011; Watkins \& Mazur, 2013).

Student benefits from undergraduate research experiences are well-documented (Adams et al., 2006; Healey, 2005; Seymour, Hunter, Laursen, $\&$ Deantoni, 2004) and include understanding the nature and development of scientific knowledge, recognizing that knowledge is complex and can be uncertain, and viewing knowledge critically (Healey, Jenkins, \& Lea, 2014; Magolda, 2006; Seymour et al., 2004). Undergraduate research projects are one way to give students the experience of knowledge 
construction and the realization that they are themselves a source of knowledge (Thiry et al., 2011). First-year university students tend to view knowledge as certain, finite and explicit, and look towards external authorities, such as instructors, as holders of knowledge (Abd-El-Khalick, 2006; Hofer, 2004; Schommer, 1993; Tsai, 1999). These views are inconsistent with the epistemic goals of undergraduate science education. In order to correct students' naïve views of knowledge over their undergraduate degrees, it is important to engage them in the research process from their first year (Healey et al., 2014). Further, Rodenbusch, Hernandez, Simmons, and Dolan (2016) recently found that first-year science, technology, engineering, or math (STEM) students who participate in a one-year research experience are more likely to graduate with a STEM degree than their peers who did not have a one-year research experience. This paper describes a two-course sequence that provides opportunities for first-year science students to engage in research and present at a student-led research conference.

We designed a multidisciplinary research experience in a two-course sequence for first-year science students as part of an enriched first-year program. The overall goal is to engage students in research, and through that process, foster sophisticated epistemic views of scientific knowledge - namely, that it is created, not handed down; that it is complex and uncertain, not simple and certain; and that it is something students are capable of contributing to, not the property of an external authority (Magolda, 2006). Drawing on the notion of Community of Practice (Lave \& Wenger, 1991), this course sequence engages a cohort of students and their faculty mentors in an authentic first-year research experience. Students collaborate on projects under the guidance of a faculty mentor, with the aim of adopting an apprenticeship model where the faculty mentor encourages every student in the program, as apprentice scholars, to adopt multidisciplinary lenses as they pursue a project of their own interest (Rogoff, 1990).

The course sequence has been offered twice, and although the overall goal of the course remained consistent over the two offerings, the curriculum changed significantly from Year 1 to Year 2. These changes were mainly driven by instructor reflections and student comments and were intended to address challenges faced in Year 1.

In this paper, we address two questions: 1) to what extent were the course goals achieved and 2) what impact did the curriculum changes have? Before addressing these two questions, we outline the goals for the course and describe the course context and curriculum for Year 1 and 2.

\section{Course Goals and Learning Outcomes}

An interdisciplinary team of instructors from the Faculties of Arts, Education, and Science at the University of British Columbia developed the courselevel goals for this sequence of first-year research project courses. The first course in this sequence (VANT 148) was designed to provide students with opportunities to:

- extend discipline specific classroom learning;

- transition to University and undertake apprentice scholarship;

- engage in multidisciplinary ways of knowing;

- apply course concepts through project-based learning, including the creation of learning artifacts for both peers and the wider UBC community;

- acquire and improve English for Academic Purposes;

- work with a faculty mentor; and

- be motivated and inspired to pursue courses of their interest in their $2^{\text {nd }}$ year.

The second course in this sequence (VANT 149) included a student-led academic conference experience and was designed to provide students with opportunities to:

- participate in multidisciplinary discussions with their peers (both within and outside their selected discipline) on current theories and issues;

- extend their classroom learning by formulating and proposing a collaborative, novice research project under the guidance of 
their faculty mentors;

- do research and present to their peers as apprentice scholars at the capstone conference;

- acquire professional skills, including event planning, networking, leadership, and teamwork; and

- further develop their English for Academic Purposes.

The overall goal for this two-course sequence was to engage students in research and foster sophisticated epistemic views. This goal was broken down into four main student learning outcomes (Table 1).

\section{Course Context and Curriculum}

Students in Vantage One Science are all first-year science students, English language learners, and are typically from outside of Canada and the United States. The Vantage One program is taught in small class sizes, with tutorial sections of 15-26 students and lecture sections with typically fewer than 75 students. Students in the program are all enrolled in the same core courses and have some choice of electives. The core of the Vantage One program includes embedded Academic English courses. The instructors who teach in the program have multiple opportunities to work with colleagues across disciplines. The Vantage One program is a first-year program at the University of British Columbia, a large research-intensive university.

As shown in Figure 1, the VANT 148/149 course sequence takes place over three terms. It is taught by a team of five instructors from Chemistry, Computer Science, Earth Sciences, Mathematics, and Physics. In terms 1 and 2, students describe and explore the elements involved in the research process, understand key similarities and differences in research across disciplines, and extend discipline-specific concepts (VANT 148). In term 3, students apply the elements involved in research to carry out a research project and present their findings at a student-led academic research conference (VANT 149).

\section{Table 1}

VANT 148 and VANT 149 Student Learning Outcomes

\begin{tabular}{ll}
$\begin{array}{l}\text { Learning } \\
\text { Outcome 1 }\end{array}$ & $\begin{array}{l}\text { Describe and apply the elements involved in the research process. These elements include } \\
\text { developing a research question, finding literature to support your research, collecting "data" } \\
\text { (recognizing that data may be quite different across the disciplines), judging the statistical } \\
\text { relevance of data, and disseminating your work. }\end{array}$ \\
\hline $\begin{array}{l}\text { Learning } \\
\text { Outcome 2 }\end{array}$ & $\begin{array}{l}\text { Understand key disciplinary differences and overlap in research, particularly with what } \\
\text { constitutes as data. }\end{array}$ \\
\hline $\begin{array}{l}\text { Learning } \\
\text { Outcome 3 }\end{array}$ & Extend discipline-specific concepts learned in class. \\
\hline $\begin{array}{l}\text { Learning } \\
\text { Outcome } 4\end{array}$ & Carry out a research project in pairs and present that research to peers. \\
\hline
\end{tabular}



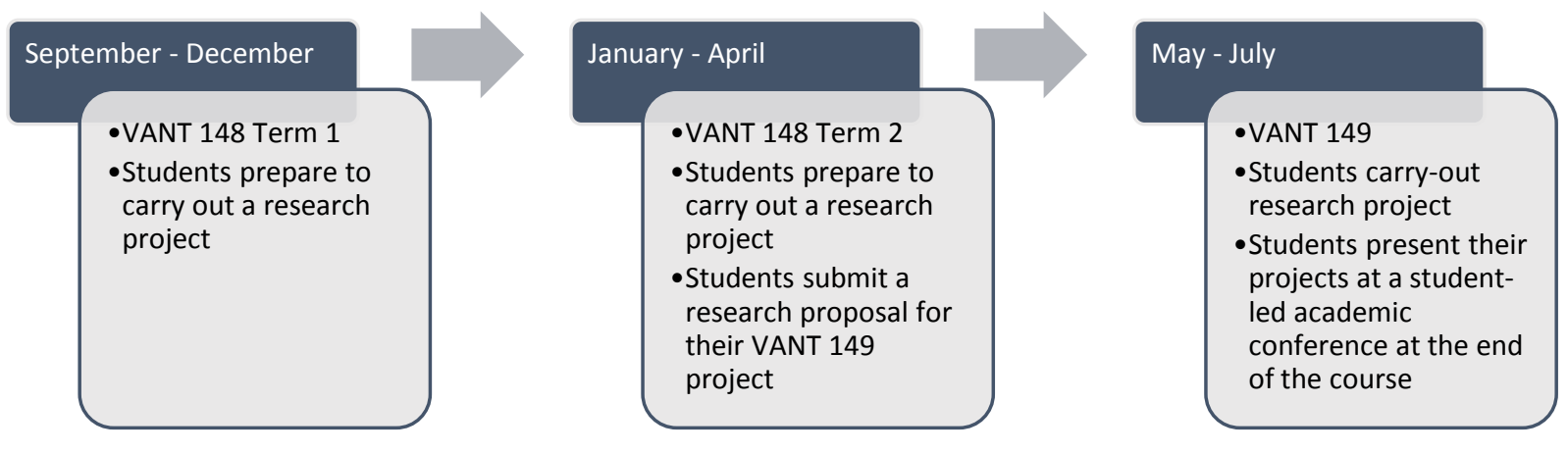

Figure 1

Timeline of Course Sequence

\section{VANT 148}

VANT 148 is the first course of the two-course sequence. It takes place over two terms ( 8 months) and consists of activities that prepare students to carry out their research project in VANT 149. The last assignment in VANT 148 is for students to submit a research proposal. Although the student learning outcomes for VANT 148 remained consistent, the curriculum in Year 1 and Year 2 differed considerably. These changes were mainly driven by instructor reflections and were intended to address challenges faced in Year 1.

\section{Year 1 (Pilot Year)}

The curriculum approach in Year 1 was to discuss broad research themes, embed examples of disciplinespecific research, and rely on continuous, individualized faculty mentorship to support students. This modelled a traditional academic research experience in which a small number of students work closely with a single supervisor. We also used an experiential pedagogical approach in which students were assigned to make a meaningful measurement to answer a simple question in the second week of the term. Their measurement served as a concrete example for them to revisit throughout the term.
The course structure included bi-weekly, 1.5-hour lectures with the whole cohort (approximately 100 students). In term 1, the lectures revolved around generating a research question. Within each lecture, research questions from different disciplines were discussed. For example, the Chemistry-themed lecture included examples of questions such as, "How can we speed up the degradation of polymers?" and "How can we make a drug more bioavailable?" In addition, each lecture included personal research stories. In term 2 , the biweekly lectures revolved around the research process. Topics in term 2 included "the importance of consulting literature in research" and "how to read a research article". The team of instructors delivered the bi-weekly lectures in rotation, but all instructors were present and participated in all lectures.

In addition to the bi-weekly lectures, students also attended weekly one-hour seminars of 15-26 students in term 1 and small group meetings of 2-4 students in term 2 . The seminars and meetings were all led by an instructor.

In term 1, students evaluated their initial measurement assignment in relation to the seminar's topic. For example, during the seminar on "Judging your results: are they statistically meaningful?", students were asked to refine their measurement for repeatability and determine an average and standard deviation. Table 2 shows an example of the topics discussed in the weekly seminar. In term 2 , students 


\section{Table 2}

Example of topics covered in the weekly seminars in term 1 of Year 1

\begin{tabular}{cl}
\hline Week & \multicolumn{1}{c}{ Weekly Meeting Topic } \\
\hline 1 & NO MEETING \\
2 & Introductions, what is research? Assignment \#1 \\
3 & Keeping a journal or logbook \\
4 & Developing a research question and identifying the relevance of a research project \\
5 & Designing a procedure and collecting data and observations \\
7 & Finding literature to support your research and theorizing your research \\
8 & Identifying limitations of a research project \\
9 & Illustrating your results \\
13 & Peer review process: giving and receiving feedback \\
11 & Project feedback exchange
\end{tabular}

summarized pre-selected entry-level research articles so that they could practice reading scientific literature. In preparation for their research in term 3, students also identified their research question, completed a literature review for their research question, and followed a template to write a research proposal. All assignments were completed in pairs and consisted of two drafts. During the group meetings, the instructor led discussions on how to improve first drafts. The assignments are summarized in Table 3.

\section{Year 2}

The same instructor team from Year 1 taught in Year 2. In Year 2, there was less reliance on faculty to provide continuous and individualized support for student project development, and more front-end support. Similar content was presented, but in term 1 it was delivered in discipline-specific modules with examples of the research process embedded into each discipline. This was followed in term 2 by modules on broader themes, including Data Collection, Literature Review, and Writing a Research Proposal. Each three-week module included a pre-assignment, a lecture with the entire cohort led by one or two instructors, a post-assignment, and office hours (Table 3). The post-assignment in each module included a research-related task. For example, students were given data from a particular discipline and asked to represent the results in a meaningful way. Figure 2 provides an overview of the Chemistry module as an example. Instructors developed and delivered the module that related to their own 
Table 3

Summary of Assignments in VANT 148 and VANT 149 for Year 1 and Year 2

\begin{tabular}{|c|c|c|}
\hline \multicolumn{3}{|c|}{ Assignment List } \\
\hline & Year 1 (Pilot Year) & Year 2 \\
\hline $\begin{array}{ll}\text { VANT } 148 \\
\text { Term } 1\end{array}$ & $\begin{array}{l}\text { - A one-page report summarizing a } \\
\text { measurement (individual) } \\
\text { - Note-taking during large lectures } \\
\text { (individual) } \\
\text { - Report on a } 2^{\text {nd }} \text { measurement - Draft } \\
1 \text { (pairs) } \\
\text { - Report on a } 2^{\text {nd }} \text { measurement - Final } \\
\text { draft (pairs) }\end{array}$ & $\begin{array}{l}\text { - Computer Science module: pre- and post- } \\
\text { class assignment (individual) } \\
\text { - Earth Sciences module: pre- and post-class } \\
\text { assignment (individual) } \\
\text { - Math module: pre- and post-class } \\
\text { assignment (individual) } \\
\text { - Data Collection module: pre-class } \\
\text { assignment (individual) and report on a } \\
\text { measurement (pairs) }\end{array}$ \\
\hline $\begin{array}{ll}\text { VANT } 148 \\
\text { Term } 2\end{array}$ & $\begin{array}{l}\text { - } \text { Read and summarize two provided } \\
\text { research articles (individual) } \\
\text { - } \quad \text { Topic Proposal for VANT } 149 \\
\text { project (pairs) } \\
\text { - } \quad \text { Read and summarize one research } \\
\text { article related to your project } \\
\text { (individual) } \\
\text { - } \quad \text { Write a literature review containing } \\
\text { three research articles for your VANT } \\
149 \text { project (pairs) } \\
\text { - } \quad \text { Research proposal - Draft } 1 \text { (pairs) } \\
\text { - } \quad \text { Research proposal - Draft } 2 \text { (pairs) }\end{array}$ & $\begin{array}{l}\text { - Physics module: pre- and post-class } \\
\text { assignment (individual) } \\
\text { - Chemistry module: pre- and post-class } \\
\text { assignment (individual) } \\
\text { - Literature Review module: Submit a } \\
\text { research question for VANT } 149 \text { and find } \\
\text { one article related to proposed research } \\
\text { question (individual) } \\
\text { - Research proposal module: Drafts } 1 \text { and } 2 \\
\text { of a research proposal (pairs) }\end{array}$ \\
\hline VANT 149 & $\begin{array}{l}\text { - A short paragraph sur } \\
\text { - } \text { Submission of prelim } \\
\text { - A short paragraph des } \\
\text { - } \text { Research report - Dra } \\
\text { - } \text { Research report - Fin } \\
\text { - } \text { Presentation material } \\
\text { - Conference presentati } \\
\text { - } \quad \text { Peer evaluation of pre }\end{array}$ & $\begin{array}{l}\text { Imarizing research plan and progress update } \\
\text { nary data } \\
\text { cribing data interpretation } \\
\text { t } 1 \\
1 \text { draft } \\
\text { (either slides or poster) } \\
\text { on } \\
\text { sentations }\end{array}$ \\
\hline
\end{tabular}


Pre-Assignment

- Students assigned to read and watch videos on hydrophobicity and answer questions before class.

- Students assigned to come up with their own research question related to the hydrophobicity of different materials and to bring their own materials.
Lecture

- A short lecture on examples of research in chemistry.

- Students measure hydrophobicity of their materials.

- A short lecture on the case study discussed in the post-assignment.
Post-Assignment

- Students present and interpret their hydrophobicity data.

- In a case study, students are given data for oceanic dissolved iron measurements and concentrations of atmospheric carbon dioxide. Students are asked to create a calibration curve and use a $t$-test to interpret the data and results.

Figure 2

Sample module in VANT 148 Year 2 (the Chemistry module)

discipline and contributed to at least one of the broader research process modules. During the last module, students wrote a research proposal for the project that they would complete in VANT 149.

\section{VANT 149}

The curriculum for VANT 149 was centered on individualized faculty mentorship in both Year 1 and Year 2. Students worked in pairs to conduct the research that they proposed in term 2 and to write a report on their project with the help of a template. Each pair was matched with one instructor mentor, who provided feedback and graded the project. Throughout the course, students met with their mentor in groups of two to four to discuss their data, the interpretation of the data, and drafts of the report, as shown in Table 3.

Academic English faculty members provided students with a series of presentation skills workshops. At the end of the term, students presented their work to their peers via an oral or poster presentation at a two-day, student-led academic conference. The training in presentation skills and the experience of giving a conference presentation is particularly useful for international students who generally, have not had the opportunity in high school. While low-stakes in terms of assessment, the student conference offered students a highly impactful and authentic opportunity. More than 150 students from two faculties attended the conference in Year 1 and more than 250 students from four faculties attended the conference in Year 2. Students were required to attend other presentations, ask questions, and write reflections. 


\section{Course Evaluation}

\section{Methods}

The course was evaluated to determine how well the course goals were achieved, and whether the curriculum changes between Years 1 and 2 had an impact. We examined student survey data, instructor observations and reflections, and student performance. Student survey data was collected at the end of VANT 148 in both Year 1 and Year 2. The survey consisted of Likert-scale items which asked students to rank their satisfaction with course activities, as well as open-ended questions which asked students to describe their views on VANT 148 and research in general. In Year 1, 57 of the 88 students $(65 \%)$ responded to the survey and in Year 2 , 65 of the 82 students (79\%) responded to the survey. The surveys were administered in class, and only students who attended that class participated in the survey. Two instructors coded responses to the open-ended questions into common themes. Instructor observations and reflections were collected during weekly meetings for both Year 1 and Year 2 as well as at end-of-term planning meetings. Student performance was assessed by the VANT 149 project reports, presentations, and quality of participation in the student conference.

\section{To What Extent Were Course Goals and Student Learning Outcomes Achieved?}

The overall goal of the course sequence is to engage students in research and foster sophisticated epistemic views. As shown in Table 1, we broke this goal down into four student learning outcomes: (a) describe and apply the elements of research, (b) understand key disciplinary differences and overlap in research, (c) extend discipline-specific concepts, and (d) carry out a research project and presentation.

Based on the quality of students' assignments, presentations at the student-led conference, and participation in the conference, the instructors assessed that students engaged meaningfully with the research process and began to understand how scientific knowledge is created. For example, students were able to use their data and literature to discuss with peers in other faculties how they knew what they knew about their research. Student responses to the open-ended survey questions in both Year 1 and Year 2 indicate a sophisticated view of knowledge construction. When students were asked to describe what is involved in doing scientific research, they provided high-level descriptions such as portrayals of collaborations, using curiosity and literature to frame research questions, and using literature and statistics to explain and evaluate results. For example, one student wrote: "thinking of a research question, looking for sources, making plans, and group work". Another student answered, "passion, curiosity, collecting data and analyzing it, a lot of reading." It is difficult to observe from student performance whether the course fostered other sophisticated epistemic views such as seeing knowledge as complex and uncertain or seeing oneself as capable of contributing to knowledge.

Although the overall goal seems to have been achieved, students had challenges meeting two of the four learning outcomes. The quality of students' research questions and written reports indicate that students had difficulty applying elements involved in the research process - most notably, filtering information and finding literature to support their research. Students also had difficulty extending discipline-specific concepts; many research projects were flawed in content and would not be considered publishable. On the other hand, most students' reports contained the main elements that characterize authentic research papers: a research question; motivation and context; a discussion of literature; a description of the experiment or other methods; a discussion of results; and a brief conclusion. These instructor observations were consistent with student survey results. In Year 1, students reported that they found it most difficult to come up with a research question and find and read literature. In Year 2, students reported that they found it most difficult to come up with a research question and engage with assignments that extended what they learned in their discipline-specific courses. 


\section{What Impact did the Curriculum Change Have?}

There were three main differences in the curriculum between Year 1 and Year 2 for VANT 148. The first difference was that in Year 1 students were not given a significant amount of up-front support. Instead, we relied on individualized faculty mentorship as in a traditional academic research experience. Instructors spent hours providing support throughout the course to small groups of students. In Year 2, there was much more front-end support and less individualized support. The second difference was the overall structure of the course. In Year 1, we used research themes as the common thread in VANT 148 with embedded discipline-specific examples. In Year 2, we used a modular approach, with a combination of five discipline-specific modules with embedded research themes, and three research-themed modules. The third difference was an adjustment of the instructors' expectations for how the students would engage with current literature and demonstrate originality in their research. In Year 1, we expected our students to be able to conduct novel, but small, research projects. We soon realized that it is unrealistic to expect a cohort of first-year students to conduct novel research. We adjusted our expectations for Year 2 and instead expected our students to be able to conduct research projects that are new to them, but not necessarily novel.

\section{Impact on Students}

In both offerings, the quality of the research projects and reports submitted for VANT 149 were consistent. The curriculum changes in VANT 148 did not have a significant impact on student performance. In both years, VANT 148 was able to prepare students to a similar degree for VANT 149. This is supported by the survey data from the end of VANT 148. Students were asked how their confidence in undertaking research changed. In 2014, $84 \%$ of students reported that their self-confidence increased a little or a lot; in $2015,70 \%$ of students reported that their self-confidence increased a little or a lot.

In Year 1, 64\% of students reported that they found working with an instructor mentor in small groups of two to four to be the most helpful activity. This may be because students tend to compartmentalize their learning (Edmondson \& Novak, 1993), but mentorship interactions facilitate connections between course content and student projects. In Year 2, when there were fewer opportunities for small group mentorship, students reported in the surveys that they wished they had more such opportunities. Based on this feedback, we are exploring a hybrid approach for Year 3. We plan to continue using the modular approach with frontend support via example research questions and templates, but also include small group mentorship opportunities early in VANT 148.

\section{Impact on Instructors}

The most significant effect between the two curricula is in instructor satisfaction and workload. In Year 1, instructors did not anticipate how challenging the research process would be for this population of firstyear international students. As a result, we did not offer much guidance or support at the start of the course but responded to student needs by providing a great deal of individualized feedback and direction through mentorship in term 2. In Year 2, we reformatted the course to offer more of that support up front. For example, in Year 1, instructors spent hours guiding students to develop a suitable research question. At the end of this process, the research questions were nevertheless mainly instructor generated. In Year 2, we provided potential research questions during the discipline-specific modules which students could build upon for their research projects. We also learned to include clear examples of how research is conducted. During the bi-weekly lectures in Year 1, students were given examples of research questions but little detail on how research is executed. In Year 2, the instructors assigned scaffolded, mini-research tasks in each module as examples of the research process. Finally, we found that students had difficulty formatting their 
submissions. In Year 2, the instructors provided more examples and templates for research proposals and reports.

\section{Instructor Reflections on Curriculum Changes}

Though there were benefits to both approaches, the instructors determined that the approach in Year 2 was better. The themed bi-weekly lecture series and term 1 seminars in Year 1 lacked context and were too abstract. Students were not able to apply concepts discussed in class to their own research projects. This is supported by survey data: $61 \%$ of students in Year 1 reported that the least helpful activity was the biweekly lectures. Even after a seminar discussion on how to determine if results were statistically meaningful, students were not able to recognize that they should repeat their measurements and analyze the standard deviation of their results. All instructors were involved with every activity in Year 1. By the end of term 2, instructors felt overworked in relation to other courses with similar credit counts. The modular approach in Year 2 was much more manageable. There were more assignments, which helped keep students engaged. Instructors were in charge only of the module that related to their own discipline and one other module. Each module also demonstrated research tools and examples in the context of a specific disciplinary topic. Students found this more accessible, as evidenced by more students applying those tools when they worked on their own projects.

The instructors also adjusted expectations by de-emphasizing engagement with the research literature and removing the requirement of originality. Instructors recognized how difficult it is for first-year students to engage with current literature when they do not yet have enough content knowledge. This difficulty is exacerbated by a lack of familiarity with the academic English used in most papers. In Year 2, there was still an expectation for students to use current literature, but secondary and tertiary sources were explicitly allowed. The requirement to use more than three sources was also lifted. By adjusting expectations, instructors were able to spend less time supporting students in understanding research articles and more time on other elements of the research process. Removing the expectation of originality reflected that first-year students can still learn a lot about research if they undergo a project in which the question is new to them, rather than to the field (Thiry, Weston, Laursen, \& Hunter, 2012).

\section{Summary and Lessons Learned}

A multidisciplinary course in which first-year students engage in research and present their research to peers is valuable. Based on the quality of student performance and student survey responses, the instructors conclude that students did indeed engage meaningfully with the research process and began to understand how scientific knowledge is created.

In term 1 and term 2 of our three-term course sequence, students describe and explore the elements involved in the research process, are given opportunities to observe key similarities and differences in research across disciplines, and extend discipline-specific concepts (VANT 148). In term 3, students apply the elements involved in research to carry out research under the guidance of a faculty member and present their findings to their peers (VANT 149). Two different curricula were used in Year 1 and Year 2 in VANT 148 to achieve the same outcomes and prepare students for VANT 149. In Year 1, faculty delivered course content and provided individualized mentorship with little front-end support. In Year 2, the course content was reorganized into discipline-specific modules and students were provided with more front-end support in addition to faculty mentorship. Both curricula seemed to support students' preparation for VANT 149, but instructors found that the structure in Year 2 allowed for a more even and manageable workload. On the other hand, students prefer more small-group time with an instructor in VANT 148. We plan to keep the modular structure with front-end support in the future, but also to provide more opportunities for small group interactions.

We encourage instructors thinking of delivering a similar research-based course for first-year 
students to provide front-end support via example research questions and report templates. We also suggest de-emphasizing literature review (but still include some engagement with literature), removing any expectations of original research for first-year students, and incorporating small group mentorship opportunities early in the course sequence.

\section{References}

Abd-El-Khalick, F. (2006). Over and over again: College students' views of nature of science. In L. B. Flick \& N. G. Lederman (Eds.), Scientific inquiry and nature of science: Implications for teaching, learning, and teacher education (pp. 389-425). Dordrecht, Netherlands: Springer

Adams, W. K., Perkins, K. K., Podolefsky, N. S., Dubson, M., Finkelstein, N. D., \& Wieman, C. E. (2006). New instrument for measuring student beliefs about physics and learning physics: The Colorado Learning Attitudes About Science Survey. Physical Review Special Topics - Physics Education Research, 2(1), 010101. VIEW ITEM

Edmondson, K. M., \& Novak, J. D. (1993). The interplay of scientific epistemological views, learning strategies, and attitudes of college students. Journal of Research in Science Teaching, 30(6), 547-559. VIEW ITEM

Fox, J., Birol, G., Han, A., Cassidy, A., Welsh, A., Nakonechny, J., ... Samuels, L. (2014). 2013 Alan Blizzard Award Feature Article Enriching educational experiences through UBC's first year seminar in science (SCIE113). Collected Essays on Learning and Teaching, 7(1), 1-18. VIEW ITEM

Healey, M. (2005). Linking research and teaching: Exploring disciplinary spaces and the role of inquiry-based learning. In R. Barnett (Ed.), Reshaping the university: New relationships between research, scholarship and teaching (pp.
67-78). New York (NY): Society for Research into Higher Education \& Open University Press

Healey, M., \& Jenkins, A. (2009). Developing undergraduate research and inquiry. York, UK: Higher Education Academy. VIEW ITEM

Healey, M., Jenkins, A., \& Lea, J. (2014). Developing research-based curricula in college-based higher education. York, UK: Higher Education Academy. VIEW ITEM

Hofer, B. K. (2004). Exploring the dimensions of personal epistemology in differing classroom contexts: Student interpretations during the first year of college. Contemporary Educational Psychology, 29(2), 129-163. VIEW ITEM

Hofer, B. K., \& Pintrich, P. R. (1997). The development of epistemological theories: Beliefs about knowledge and knowing and their relation to learning. Review of Educational Research, 67(1), 88-140. VIEW ITEM

Lave, J., \& Wenger, E. (1991). Situated learning: Legitimate peripheral participation. Cambridge: Cambridge University Press.

Magolda, M. B. B. (2006). Intellectual development in the college years. Change: The Magazine of Higher Learning, 38(3), 50-54. VIEW ITEM

Rodenbusch, S. E., Hernandez, P. R., Simmons, S. L., \& Dolan, E. L. (2016). Early engagement in course-based research increases graduation rates and completion of science, engineering, and mathematics degrees. CBE-Life Sciences Education, 15(2), ar20. VIEW ITEM

Rogoff, B. (1990). Apprenticeship in thinking: Cognitive development in social context $\left(2^{\text {nd }} \mathrm{Ed}\right.$.). London, UK: Oxford University Press.

Schalk, K. A., McGinnis, J. R., Harring, J. R., Hendrickson, A., \& Smith, A. C. (2009). The undergraduate teaching assistant experience 
offers opportunities similar to the undergraduate research experience. Journal of Microbiology \& Biology Education, 10(1), 3242. VIEW ITEM

Schommer, M. (1993). Comparisons of beliefs about the nature of knowledge and learning among postsecondary students. Research in Higher Education, 34(3), 355-370. VIEW ITEM

Seymour, E., Hunter, A. B., Laursen, S. L., \& Deantoni, T. (2004). Establishing the benefits of research experiences for undergraduates in the sciences: First findings from a three-year study. Science Education, 88(4), 493-534. VIEW ITEM

Thiry, H., Laursen, S. L., \& Hunter, A. -B. (2011). What experiences help students become scientists? A comparative study of research and other sources of personal and professional gains for STEM undergraduates. The Journal of Higher Education, 82(4), 357-388. VIEW ITEM

Thiry, H., Weston, T. J., Laursen, S. L., \& Hunter, A. -B. (2012). The benefits of multi-year research experiences: Differences in novice and experienced students' reported gains from undergraduate research. CBE-Life Sciences Education, 11(3), 260-272. VIEW ITEM

Tsai, C.-C. (1999). The progression toward constructivist epistemological views of science: A case study of the STS instruction of Taiwanese high school female students. International Journal of Science Education, 21(11), 1201-1222. VIEW ITEM

Watkins, J., \& Mazur, E. (2013). Retaining students in science, technology, engineering, and mathematics (STEM) majors. Journal of College Science Teaching, 42(5), 36-41. VIEW ITEM
Wieman, C. (2012). Applying new research to improve science education. Issues in Science and Technology, 29(1), 25-32. VIEW ITEM

\section{Acknowledgements}

The authors gratefully acknowledge our colleagues Steven Barnes, Alfredo Ferreira, Joss Ives, Siobhán McPhee, Jenny Peterson, Jaclyn Rea, Brian Wilson and Sandra Zappa-Hollman for their contributions to planning the course-level goals for this sequence of first-year research project courses.

\section{Biographies}

Priyanka Lekhi teaches in the Vantage One program and is a member of the Department of Chemistry at the University of British Columbia.

Meghan Allen teaches in the Vantage One program and is a member of the Department of Computer Science at the University of British Columbia.

Fok-Shuen Leung teaches in the Vantage One program and is a member of the Department of Mathematics at the University of British Columbia.

Brett Gilley teaches in the Vantage One program and is a member of the Department of Earth, Ocean and Atmospheric Sciences at the University of British Columbia.

Georg Rieger teaches in the Vantage One program and is a member of the Department of Physics and Astronomy at the University of British Columbia.

Joanne A. Fox is Principal of UBC Vantage College and a member of the Michael Smith Laboratories and the Department of Microbiology and Immunology at the University of British Columbia. 